\title{
Perfil etiológico das diarréias agudas de crianças atendidas em São Paulo
}

\author{
Etiologic profile of acute diarrhea in children in the city of São Paulo \\ Eloisa C. Souza ${ }^{1}$, Marina B. Martinez ${ }^{2}$, Carla R. Taddei ${ }^{3}$, Lilian Mukai ${ }^{4}$, Alfredo E. Gilio ${ }^{5}$, \\ Maria L. Racz' ${ }^{6}$, Luzinete Silva ${ }^{6}$, Bernardo Ejzenberg ${ }^{7}$, Yassuhiko Okay ${ }^{8}$
}

\section{Resumo}

Objetivo: determinar o perfil etiológico das diarréias agudas de um grupo de crianças de baixo nível socioeconômico atendidas em um serviço regional de pronto-atendimento pediátrico.

Método: durante dois anos, as crianças com diarréia aguda atendidas durante um horário pré- estabelecido do dia e da semana foram incluídas no estudo. Os outros critérios seletivos eram: a) idade inferior a 5 anos; b) não utilização de antibiótico no mês precedente; c) ausência de viagem para fora da cidade no mês precedente. Foram pesquisados nas fezes: a) rotavírus (imunofluorescência e contra-imunoeletroforese); b) bactérias cultura em ágar MacConkey, ágar SS, ágar Columbia, verde brilhante, soroaglutinação, detecção de toxinas - INV, LT,ST,SLT I, SLT II, teste de Séreny, detecção de fatores de virulência - EAF, eae ,BFP; c) protozoários (Hoffman e Faust). No mesmo período, um grupo controle sem diarréia foi também avaliado para os mesmos patógenos fecais.

Resultados: no período de março de 1994 a junho de 1996, foram selecionadas para o estudo 154 crianças com diarréia aguda (GDA) e 42 crianças sem diarréia (GSDA). Foram detectados agentes enteropatogênicos em 112 casos $(72,8 \%)$ do GDA, e em 9 (21,5\%) do GSDA. A associação de dois ou mais enteropatógenos ocorreu em 47 (30,5\%) casos do GDA, e em $3(7,1 \%)$ do GSDA. Os patógenos encontrados por caso, do GDA, foram: rotavírus $32(20,8 \%)$, bactérias $53(34,4 \%)$, ambos $25(16,2 \%)$, e $2(1,4 \%)$ com Giardia lamblia (em um caso associada a rotavírus e noutro à bactéria). No GSDA, foram detectadas bactérias em 8 casos (19,1\%), e bactéria associada à Giardia lamblia em $1(2,4 \%)$ caso. Das 105 bactérias isoladas no GDA, 90 eram Escherichia coli (EPEC 27, DAEC 24, ETEC 21, EAEC 18), 12 eram Shigella sp, 2 eram Salmonella sp, e uma era Yersinia sp. As crianças com infecção mista - viral e bacteriana apresentaram maior ocorrência de vômitos repetidos, desidratação e internação.

Conclusões: as bactérias foram os enteropatógenos mais detectados nos casos de diarréia aguda, sendo a Escherichia coli a mais freqüente. $\mathrm{Na}$ maior parte, as cepas de Escherichia coli eram de biovariedade não-EPEC, habitualmente não investigadas nos laboratórios de patologia clínica. O rotavírus foi encontrado em grande parcela dos casos, muitas vezes em associação com as bactérias. Os protozoários tiveram importância reduzida.

J Pediatr (Rio J) 2002; 78 (1): 31-38: diarréia, vírus, bactéria, protozoários.

\begin{abstract}
Objective: to evaluate the etiologic profile of acute diarrhea in socioeconomically deprived children assisted at a regional pediatric emergency care service.

Methods: during two years all children with acute diarrhea assisted at a previously established day and week time schedule were included in the study. Other selective criteria were: a) age less than 5 years; b) nonuse of antibiotics in the previous month; and c) no travel outside the city in the previous month. Stool examination was used for the detection of the following microorganisms: a) rotavirus (immunofluorescence and counterimmunoelectrophoresis); b) bacteria - culture in MacConkey agar, SS agar, Columbia agar, bright green, serotyping, detection of toxins - INV, LT,ST,SLT I, SLT II, Sereny test, detection of virulence factors- EAF, eae, BFP; and c) protozoa (Hoffman and Faust). In the same period, a control group without diarrhea was also evaluated for the same fecal pathogens.

Results: between March 1994 and June 1996, 154 children with acute diarrhea (AD) and 42 control children (WAD), that is, without acute diarrhea, were selected. In the AD group, intestinal pathogens were detected in $112(72.8 \%)$ cases, and in $9(21.5 \%)$ cases in the WAD group. The association of two or more intestinal pathogens occurred in $47(30.5 \%)$ cases in the AD group, and in $3(7.1 \%)$ cases in the WAD group. The pathogens identified in the AD cases were: Rotavirus: 32 (20.8\%), bacteria: 53 (34.4\%), both: $25(16.2 \%)$, and $2(1.4 \%)$ with Giardia lamblia (in one case associated with Rotavirus and in another one associated with bacteria). In the WAD group, only bacteria were detected in $8(19.1 \%)$ cases, and bacteria associated with Giardia lamblia in 1 (2.4\%) case. Altogether, there were 105 bacteria isolated in the AD group: 90 were Escherichia coli (EPEC 27, DAEC 24, ETEC 21, EAEC 18), 12 were Shigella sp, 2 were Salmonella sp, and one was Yersinia sp. Children with mixed infections (viral and bacterial) had increased incidence of severe vomiting, dehydration and hospitalization.

Conclusions: bacteria were the most frequent pathogens detected in acute diarrhea cases, among which Escherichia coli was highly predominant. The majority of Escherichia coli strains belong to non-EPEC varieties, strains that are not routinely evaluated in clinical laboratories of pathology. Rotavirus was found in a great number of diarrhea cases, often associated with bacteria. Protozoa showed reduced importance.
\end{abstract}

J Pediatr (Rio J) 2002; 78 (1): 31-38: diarrhea, virus, bacteria, protozoa.

1. Mestre em Pediatria. Assistente do Serviço de Pronto-Atendimento HU-USP.

2. Professor Livre Docente em Microbiologia Clínica. Faculdade de Ciências Farmacêuticas - USP.

3. Pós-graduanda (Doutorado). Instituto de Ciências Biomédicas - USP.

4. Pediatra. Ex-Assistente do Serviço de Pronto-Atendimento do HU-USP.

5. Doutor em Pediatria. Chefe da Enfermaria de Pediatria do HU-USP.

6. Doutor em Microbiologia Clínica. Instituto de Ciências Biomédicas -USP.

7. Doutor em Pediatria. Coordenador de Pesquisas e Publicações da Divisão de Pediatria-HU-USP.

8. Professor Titular de Pediatria. Diretor da Divisão de Pediatria do HU-USP.

Artigo submetido em 29.01.01, aceito em 31.10.01. 


\section{Introdução}

A doença diarréica da criança é, ainda nos dias correntes, uma síndrome freqüente, estando entre as principais causas de consulta, internação e de letalidade, sobretudo nos países em desenvolvimento ${ }^{1-3}$. No Pronto-Atendimento do Hospital Universitário da USP, que atende à população carente do Distrito do Butantã- São Paulo, a diarréia aguda é a segunda causa de consulta e internação pediátricas nos últimos 5 anos.

A incidência anual e o perfil etiológico da diarréia em diferentes grupos populacionais podem variar, segundo diversos fatores de risco ${ }^{4-6}$. Favorecem ao aumento de incidência e à etiologia bacteriana os seguintes fatores: idade reduzida, deficiências nutricionais, práticas inadequadas de higiene física e alimentar, desmame precoce, aglomerações no domicílio e institucionais, ausência de saneamento básico nos locais de permanência, acesso a coleções hídricas contaminadas e período quente do ano (verão $)^{1,7}$. Em conseqüência, nos países desenvolvidos a freqüência de quadros diarréicos por criança é de apenas 0,5 a 2 episódios por lactente/ano, enquanto que nas regiões em desenvolvimento pode atingir até mais de 10 episódios/ $\mathrm{ano}^{7}$. O rotavírus prepondera nos países desenvolvidos, e as bactérias são mais importantes para as crianças de países em desenvolvimento ${ }^{8-12}$.

O perfil etiológico da diarréia da criança tem sofrido alterações em anos recentes, com a identificação de vários microorganismos ${ }^{13-16}$. Além disso, outras alterações relevantes deste perfil decorreram da reavaliação do papel diarreiogênico de muitas cepas de Escherichia coli antes consideradas não patogênicas. De há muito, é reconhecida a importância da Escherichia coli enteropatogênica clássica (EPEC) para a diarréia da criança, porém outras cinco categorias foram reconhecidas como enteropatogênicas: Escherichia coli enteroinvasora (EIEC), Escherichia coli enterotoxigênica (ETEC), Escherichia coli enteroagregativa (EAEC), Escherichia coli entero-hemorrágica (EHEC) e Escherichia coli de adesão difusa (DAEC) ${ }^{17,18}$. Essas diferentes biovariedades de Escherichia coli, consideradas freqüentes causadoras de diarréia em crianças, segundo alguns autores, foram ainda pouco estudadas em nosso país ${ }^{7,19,20}$.

Caracterizar o perfil etiológico da diarréia nos primeiros anos de vida tem, entre outras finalidades, o estabelecimento de políticas locais de vigilância, tratamento e profilaxia da doença diarréica ${ }^{1-3}$. Nesse sentido, têm sido estudadas as diarréias em diferentes regiões rurais e urbanas, classes socioeconômicas, estações climáticas, faixas etárias e pacientes com características específicas ${ }^{19,20}$.

Alguns estudos realizados na área urbana da cidade de São Paulo avaliaram a etiologia das diarréias agudas e mostraram uma predominância dos quadros bacterianos sobre os virais $8,10,15,21,22$. Dentre os agentes bacterianos, sempre preponderou a Escherichia coli, principalmente do grupo enteropatogênico clássico (EPEC), que chegou a ser detectada em até 30 a $40 \%$ dos casos de diarréia na década de $80^{8,21}$. Esse perfil etiológico é semelhante ao verificado, no mesmo período, em outras populações urbanas de países em desenvolvimento ${ }^{2,5,7}$. Porém, nos últimos anos, temos observado entre as crianças com diarréia atendidas em nosso serviço uma aparente tendência de crescimento relativo do papel do rotavírus. Esse aspecto, de possível alteração do perfil etiológico da diarréia, tem sido relatado em outras avaliações da etiologia da diarréia em populações urbanas carentes ${ }^{10,23,25}$. Adicionalmente, nos últimos anos, pudemos otimizar a avaliação das bactérias diarreiogênicas, a partir dos novos recursos laboratoriais disponíveis para estudo das biovariedades de Escherichia coli. Esses aspectos nos conduziram ao presente estudo, em que fizemos uma reavaliação da etiologia da diarréia entre as crianças atendidas em nosso pronto-atendimento.

\section{Métodos}

O estudo foi previamente aprovado pelas Comissões de Pesquisa e Ética do Hospital Universitário do HU-USP. Foi solicitado consentimento verbal pós-informado de todos os pais ou responsáveis para inclusão do caso no estudo.

Local e amostra: o estudo foi programado para dois anos de duração, abrangendo um horário limitado para atendimento e inclusão dos casos - entre oito e dez horas da manhã, de $2^{\mathrm{a}}$ a $5^{\mathrm{a}}$ feira, exceto feriados. Nesse período as crianças atendidas no Serviço de Pronto-Atendimento do HU-USP que preenchessem todos os seguintes critérios seriam incluídas: idade de 0 a 59 meses, com três ou mais evacuações aquosas no dia precedente, duração da diarréia inferior a 14 dias, não utilização de antibióticos no mês precedente e que não saíram da região urbana no mês precedente. Esse grupo foi denominado grupo com diarréia $(\mathrm{GDA})^{7}$. Simultaneamente foi selecionado um outro grupo de crianças, sem diarréia (GSDA). Foram incluídas neste grupo as crianças hígidas ou sem doença digestiva naquele momento, assim como na reavaliação feita após 3 a 4 dias; que não tivessem antecedente de vômito e/ou diarréia no mês anterior; que não tivessem saído da região urbana e não tivessem utilizado antimicrobiano no mês precedente. $\mathrm{O}$ período de coleta foi idêntico ao do GDA, porém restrito a um caso ao dia, o primeiro que preenchesse os critérios seletivos. A intensidade da diarréia foi classificada como grave quando a frequiência de evacuações no dia precedente havia sido igual ou superior a seis ${ }^{1,10}$.

Rotinas do protocolo: era feita uma avaliação clínica inicial e iniciada a hidratação, segundo a avaliação médica individualizada para cada caso. Os pais ou responsáveis eram, simultaneamente, submetidos a questionário padronizado a respeito do quadro clínico, dos hábitos alimentares, das condições de vida e da moradia da criança. As crianças eram pesadas ao término da fase de hidratação, segundo a avaliação clínica do médico assistente.

Amostras fecais eram obtidas das crianças do GDA e do GSDA após evacuação espontânea. O material era então 
separado: a) em meio de transporte de Cary-Blair, para estudo bacteriano; b) em frasco acrílico para congelamento e posterior pesquisa de vírus; c) em solução de formaldeído a 10\% e esfregaço em lâmina, para pesquisa de protozoários.

Das bactérias enteropatogênicas, foram pesquisadas seis biovariedades da Escherichia coli (EPEC, EAEC, ETEC, EIEC, EHEC, DAEC), Shigella sp, Salmonella $s p$, Yersinia enterocolitica e Campylobacter jejuni. Dos agentes virais, foi pesquisado o rotavírus. Dos protozoários diarreiogênicos, foram pesquisados a Entamoeba histolitica e a Giardia lamblia.

Pesquisa bacteriológica: foi realizada no Departamento de Análises Clínicas e Toxicológicas da Faculdade de Ciências Farmacêuticas da USP. Além dos métodos clássicos de isolamento e identificação dos patógenos, foram utilizados métodos biológicos e moleculares para a pesquisa dos fatores de virulência nas amostras de Escherichia coli isoladas dos grupos com diarréia e sem diarréia ${ }^{26-28}$.

Foi utilizado o meio de ágar MacConkey para isolamento de Escherichia coli $^{27}$. Para identificação dos sorogrupos das bactérias enteropatogênicas, foi utilizada a técnica de aglutinação em lâmina a partir de uma suspensão bacteriana, segundo técnica preconizada ${ }^{27}$. As amostras identificadas bioquimicamente como Escherichia coli eram submetidas às provas de aglutinação em lâmina, com anti-soro polivalente e monovalente contra sorogrupos clássicos de Escherichia coli (EPEC) $\mathrm{O}_{26}, \mathrm{O}_{55}, \mathrm{O}_{86}, \mathrm{O}_{111}, \mathrm{O}_{114}, \mathrm{O}_{119}$, $\mathrm{O}_{125}, \mathrm{O}_{126}, \mathrm{O}_{127}, \mathrm{O}_{128}, \mathrm{O}_{142}$ e $\mathrm{O}_{158}$. As amostras que não aglutinavam com esses soros eram testadas com anti-soros contra $\mathrm{EHEC} \mathrm{O}_{157}$ e com anti-soros polivalentes e monovalentes contra sorogrupos de EIEC $\mathrm{O}_{28 \mathrm{ac}}, \mathrm{O}_{29}, \mathrm{O}_{112 \mathrm{ac}}, \mathrm{O}_{124}$, $\mathrm{O}_{136}, \mathrm{O}_{143}, \mathrm{O}_{144}, \mathrm{O}_{152}, \mathrm{O}_{164}$ e $_{167}$. Foi realizado o teste de Séreny com todas as cepas ${ }^{26}$. Nas cepas de Escherichia coli isoladas, foram pesquisados fatores de virulência: adesão (EAF, eae, BFP), invasão (INV) e toxinas (LT, ST, SLTI, e STLII). A pesquisa desses fatores de virulência foi realizada através da técnica de hibridação de colônias ${ }^{8,28}$.

A pesquisa de Salmonella $s p$ foi feita em ágar MacConkey, ágar Salmonella-Shigella (SS) e Verde Brilhante após enriquecimento em caldos Selenito e Tetrationato ${ }^{27}$. As amostras identificadas bioquimicamente, como Salmonella $s p$, foram submetidas à aglutinação com anti-soro polivalente somático. Para determinar o sorogrupo da amostra, procedia-se aos testes de aglutinação com os anti-soros para os sorogrupos A, B, $\mathrm{C}_{1}, \mathrm{C}_{2}, \mathrm{D}, \mathrm{E}\left(\mathrm{E}_{1} \mathrm{a} \mathrm{E}_{4}\right), \mathrm{F}, \mathrm{G} \mathrm{H}$, I. As amostras com prova de aglutinação negativa tinham os testes repetidos após aquecimento a $100{ }^{\circ} \mathrm{C}$.

A pesquisa de Shigella $s p$ foi realizada em ágar MacConkey e $\mathrm{SS}^{27}$. As amostras identificadas bioquimicamente como Shigella $s p$ foram submetidas à aglutinação com anti-soros polivalentes, específicos para Shigella dysenteriae (sorotipos 1 a 10), Shigella flexneri (sorotipos 1 a 6, e variantes X e Y), Shigella boydii (sorotipos 1 a 15) e Shigella sonnei (formas I e II).
A pesquisa de Yersinia enterocolitica foi realizada em ágar MacConkey e ágar SS ${ }^{27}$. As amostras identificadas bioquimicamente como Yersinia enterocolitica foram submetidas à aglutinação em lâmina com anti-soros poli e monovalentes, preparados com culturas vivas, específicas para os sorotipos $\mathrm{O}_{3}, \mathrm{O}_{5}, \mathrm{O}_{8}, \mathrm{e} \mathrm{O}_{9}$.

A pesquisa de Campylobacter $s p$ foi realizada em ágar Columbia com carvão ativado ${ }^{20}$.

Pesquisa viral: as amostras fecais foram diluídas em solução salina (1:10) e submetidas a ensaio imunoenzimático para detecção de rotavírus ${ }^{29}$. Esse exame foi realizado de acordo com as técnicas estabelecidas, utilizando kit produzido pela Fundação Oswaldo Cruz (FIOCRUZ) ${ }^{29}$. As amostras positivas eram confirmadas por eletroforese em gel de poliacrilamida (EGPA).

Pesquisa parasitológica: as pesquisas de protozoários e helmintos foram feitas pelos métodos de sedimentação (Hoffman) e de flutuação (Faust) ${ }^{30}$.

Análise estatística: as diferenças entre os grupos foram analisadas utilizando o teste de Qui-quadrado, teste exato de Fisher e o teste de Mann-Whitney para comparação de médias. Cálculo binomial foi utilizado para estimar a distribuição de algumas proporções. Em todos os testes, foram considerados significantes os resultados com $\mathrm{p}<0,05$.

\section{Resultados}

No período compreendido entre março de 1994 a junho de 1996, foram incluídas no estudo 196 crianças atendidas no Pronto-Atendimento de Pediatria do HU-USP, sendo que 154 preencheram os critérios seletivos do GDA, e 42, do GSDA. As crianças do GSDA retornaram após 3 a 4 dias da inclusão, não sendo relatada a ocorrência de diarréia.

As crianças do GDA eram, em sua maior parte, do sexo masculino ( 85 casos $-55,2 \%$ ), menores de 1 ano ( 100 casos $-65 \%$ ), eutróficas (131 casos $-85,1 \%$ ) e não estavam em amamentação natural (123 casos - 79,8\%). No GSDA, havia 19 crianças do sexo masculino $(45,2 \%)$, a sua maioria acima de 1 ano ( 25 casos $-59,5 \%$ ) e eutróficas ( 37 casos $88 \%)$. Das 42 crianças do GSDA, apenas $11(26,2 \%)$ estavam em amamentação natural. Nesse grupo, 21 casos (50\%) não apresentavam qualquer doença, tendo comparecido para controle clínico. As outras 21 crianças apresentavam doença respiratória (13 casos - 31\%), doença de tegumento ( 6 casos $-14,3 \%$ ) ou traumatismo leve ( 2 casos $-4,7 \%)$. As características das crianças dos dois grupos estão sumarizadas na Tabela 1.

A maior parte das crianças dos dois grupos era constituída por lactentes de baixo nível socioeconômico. Embora os dois grupos tenham perfil assemelhado quanto à distribuição por sexo $(\mathrm{p}=0,25)$ e inclusão por estação climática $(\mathrm{p}=0,11)$, a distribuição etária era diversa $(\mathrm{p}=0,005)$. 
Tabela 1 - Características das crianças dos grupos com diarréia aguda e sem diarréia

\begin{tabular}{lcc}
\hline Características & GDA $(\mathbf{n = 1 5 4})$ & GDSA (n=42) \\
\hline Idade (meses) Mediana/Média & $9 / 12,4$ & $15 / 16,9$ \\
Crianças em aleitamento materno (\%) & $31(20,1 \%)$ & $11(26,2 \%)$ \\
Renda familiar ${ }^{*}$ & 3,9 & 5,2 \\
$\mathrm{~N}^{\circ}$ médio de moradores por domicílio & 4,9 & 5,0 \\
$\mathrm{~N}^{0}$ médio de crianças por domicílio & 2,3 & 2 \\
Peso >p10 & $131(85,1 \%)$ & $37(88,0 \%)$ \\
Água tratada & $151(98,0 \%)$ & $39(92,8 \%)$ \\
Esgoto encanado & $124(80,5 \%)$ & $21(13,6 \%)$ \\
Freqüência a instituições & $37(88,0 \%)$ & $2(4,7 \%)$ \\
\hline
\end{tabular}

GDA: grupo diarréia aguda; $\quad$ GSDA: grupo sem diarréia $\quad$ * em salários mínimos
Peso > p10: peso superior ao percentil 10 da curva do NCHS
† Instituições: escola ou creche, por período superior a 15 horas/semana

Sob aspecto clínico, as crianças do GDA apresentavam 3 a 12 episódios diarréicos por dia, com média de 5,8 episódios/criança/dia. Quanto à intensidade, a diarréia foi classificada como grave em 42 casos $(27,2 \%)$. Foram vistas ou relatadas fezes sanguinolentas em 17 casos $(11 \%)$. O segundo sintoma mais freqüente foi o vômito, presente em 121 crianças $(78,6 \%)$, destas, $44(28,6 \%)$ vomitaram três ou mais vezes nas 24 horas precedentes. No mesmo período, a febre foi medida ou presumida pelos responsáveis em 91 crianças (59\%). A constatação de desidratação grave ao atendimento inicial ocorreu em 37 casos $(24,0 \%)^{2}$. Após a hidratação e observação no Pronto-Atendimento, foram internadas 29 crianças $(18,8 \%)$ por um ou mais dos seguintes motivos: desidratação grave (12), diarréia com perda de grande volume líquido (18), vômitos incoercíveis (15) e mau estado geral (29).

Quanto aos resultados etiológicos, foram encontrados potenciais enteropatógenos em $112(72,8 \%)$ crianças do GDA, e em $9(21,5 \%)$ casos do GSDA. A associação entre agentes potencialmente patogênicos (de 2 a 4 por caso) ocorreu em 47 (30,6\%) casos do GDA, e em $3(7,2 \%)$ casos do GSDA. A distribuição dos casos do GDA e do GSDA, segundo as famílias dos enteropatógenos detectados, é demonstrada na Tabela 2.

Rotavírus foi detectado somente no GDA, em 58 (37,6\%) casos, em grande parte associado a bactérias - 25 casos $(16,2 \%)$. As bactérias foram detectadas em 79 casos $(51,3 \%)$ do GDA e $9(21,4 \%)$ do GSDA. As associações de bactérias ocorreram nos dois grupos. Os protozoários foram encontrados em apenas $2(1,4 \%)$ dos casos do GDA e em $1(2,4 \%)$ do GSDA. As estimativas de frequiência, calculadas por distribuição binomial, indicam proporções assemelhadas para a detecção de rotavírus, bactérias ou a associação destes enteropatógenos no grupo GDA.

Os resultados relativos aos potenciais enteropatógenos detectados nos grupos GDA e GSDA estão contidos na Tabela 3.
Foram detectados 165 patógenos potenciais no GDA $(1,1 /$ caso). No GDA, o primeiro agente em freqüência foi Escherichia coli, com 90 cepas. Como pode ser observado na Tabela 3, a maior parte, 65 destas cepas de Escherichia coli foram encontradas associadas entre si ou com outro patógeno, principalmente o rotavírus. Observa-se também que rotavírus, identificado em 58 crianças, foi o agente mais detectado isoladamente no GDA - 31 casos. Shigella sp foi isolada em 12 casos do GDA (S. flexneri-11 e S. sonnei1), associada a outro enteropatógeno em 7 crianças. Foram ainda identificadas duas crianças com Salmonella sp no GDA, e uma com Yersinia enterocolitica. Não foi detectado Campylobacter sp. O protozoário identificado no GDA foi Giardia lamblia (cistos), em apenas dois casos.

No GSDA foram detectados $12(0,3 /$ caso $)$ potenciais patógenos, sendo 11 bactérias, como se observa na Tabela 3. As bactérias eram Escherichia coli (10) e Shigella flexneri (1). Em um caso, foi detectada Giardia lamblia (cistos).

Tabela 2 - Vírus, bactérias, protozoários e helmintos detectados nos grupos com diarréia aguda e sem diarréia

\begin{tabular}{lccccc}
\hline \multirow{2}{*}{ Enteropatógenos } & \multicolumn{2}{c}{ GDA } & \multicolumn{2}{c}{ GSDA } \\
& n & \%* & $\mathbf{p}$ & $\mathbf{n}$ & \%* \\
\hline Rotavírus & 32 & 20,8 & $14,7-27,8$ & 0 & 0,0 \\
Bactérias & 33 & 21,4 & $14,9-28,6$ & 6 & 14,3 \\
Rotavírus e bactéria (s) $^{*} 25$ & 16,2 & $10,7-22,9$ & 0 & 0,0 \\
Bactéria e bactéria (s) $^{*} 20$ & 13,0 & $8,1-19,3$ & 2 & 4,8 \\
Bactéria e protozoário $^{\dagger}$ & 1 & 0,7 & $0,1-3,5$ & 1 & 2,4 \\
Rotavírus e protozoário $^{\dagger}$ & 1 & 0,7 & $0,1-3,5$ & 0 & 0,0 \\
Sem identificação $^{42}$ & 27,2 & $19,2-33,4$ & 33 & 78,5 \\
\hline Total & 154 & 100,0 & & 42 & 100,0 \\
\hline
\end{tabular}

GDA: grupo diarréia aguda; GSDA: grupo sem diarréia

* \% da coluna; p: limites da distribuição com $\mathrm{p}=0,05$

† Giardia lamblia 
Em relação às seis biovariedades de Escherichia coli pesquisadas no estudo, foram detectadas as mesmas quatro no GDA e no GSDA (Tabela 3), não sendo encontradas Escherichia coli das biovariedades EHEC e EIEC. No GSDA, foram identificadas as 90 cepas: EPEC- 27, DAEC23, ETEC- 21 e EAEC- 19. No GSDA foram identificadas as 10 cepas: EPEC- 3, ETEC- 3, EAEC- 2, DAEC- 2. As biovariedades de Escherichia coli foram encontradas como únicos potenciais enteropatógenos em frequiências assemelhadas nos dois grupos, GDA e GSDA (Tabela 3).

\section{Correlação do perfil clínico dos pacientes com aspec- tos etiológicos}

Quanto à faixa etária, as EAEC foram detectadas entre as crianças com idade inferior a 12 meses $(17 / 19, \mathrm{p}=0,02)$, e as Shigella $s p$ foram isoladas preferencialmente entre as crianças com idade superior a 1 ano $(10 / 12, p=0,004)$.

Quanto às estações climáticas, consideramos dois períodos: primavera-verão com 49 casos, e outono-inverno com 105. A EPEC ocorreu nos meses mais quentes (15/49 versus $12 / 105$, com $\mathrm{p}=0,003)$, assim como a ETEC $(15 / 49$ versus $6 / 105$, com $\mathrm{p}=0,01$ ). O rotavírus teve maior incidência nos meses do outono-inverno ( $9 / 49$ versus $49 / 105$, com $\mathrm{p}=0,001)$.

Os resultados relativos ao perfil clínico, etário e socioeconômico das crianças do GDA foram reagrupados segundo a etiologia. Foram constituídas 4 categorias: casos com rotavírus, casos com alguma bactéria, casos com rotavírus e alguma bactéria e casos sem detecção de vírus e de bactéria, como pode ser observado na Tabela 4.

$\mathrm{Na}$ análise de diversos parâmetros, não houve diferença significativa na distribuição dos resultados etiológicos em relação a diversos parâmetros dos pacientes, como idade, estado nutricional, utilização de leite materno e presença de febre. Quanto à intensidade da diarréia e à presença de sangue nas fezes, também não se observou correlação com as categorias etiológicas analisadas. Em análise bivariada, os quadros com rotavírus e bactéria, associadamente, foram correlacionados com maior freqüência de vômitos, desidratação e internação.

\section{Discussão}

\section{A fração de casos com enteropatógenos detectados}

A constatação de grande percentual de enteropatógenos no grupo GDA ( $72,8 \%$ das crianças) é similar aos melhores resultados de investigação etiológica da literatura pediátrica, que situam-se entre 60 e $80 \% 11,14$. Essencialmente, atribuímos este resultado à utilização de apurada metodologia laboratorial, que avaliou e constatou grande frequiência de Escherichia coli de biovariedades diferentes da EPEC. Foram estudadas cinco colônias de cada amostra de fezes encaminhada para investigação, enquanto nos exames convencionais são analisadas apenas duas ${ }^{27}$. Também, na avaliação das bactérias, foi realizada, além da sorotipagem
Tabela 3 - Potenciais agentes enteropatogênicos encontrados nas fezes de crianças com diarréia aguda (GDA), e sem diarréia (GSDA)

\begin{tabular}{|c|c|c|c|c|}
\hline \multirow[t]{2}{*}{ Agentes } & \multicolumn{2}{|c|}{ GDA } & \multicolumn{2}{|c|}{ GSDA } \\
\hline & $\mathbf{n}$ & $(\%)$ & $\mathbf{n}$ & $(\%)$ \\
\hline Rotavírus & 32 & $(20,8)$ & 0 & \\
\hline EPEC & 14 & $(9,1)$ & 2 & $(4,7)$ \\
\hline ETEC & 2 & $(1,3)$ & 2 & $(4,7)$ \\
\hline DAEC & 5 & $(3,2)$ & 1 & $(2,4)$ \\
\hline EAEC & 4 & $(2,6)$ & 1 & $(2,4)$ \\
\hline Shigella sp & 6 & $(3,9)$ & 0 & \\
\hline Yersinia sp & 1 & $(0,7)$ & 0 & \\
\hline Salmonella sp & 1 & $(0,7)$ & 0 & \\
\hline EPEC+ Rotavírus & 5 & $(3,2)$ & 0 & \\
\hline EPEC+ Shigella sp & 2 & $(1,3)$ & 0 & \\
\hline EPEC+ ETEC & 3 & $(1,9)$ & 0 & \\
\hline EPEC+ EAEC & 1 & $(0,7)$ & 1 & \\
\hline ETEC+ DAEC & 3 & $(1,9)$ & 0 & \\
\hline ETEC+EAEC & 2 & $(1,3)$ & 0 & \\
\hline ETEC+ Shigella sp & 1 & $(0,7)$ & 1 & $(2,4)$ \\
\hline ETEC+ GL & 1 & $(0,7)$ & 0 & \\
\hline ETEC+ Rotavírus & 5 & $(3,2)$ & 0 & \\
\hline ETEC+ EAEC +R & 2 & $(1,3)$ & 0 & \\
\hline EAEC+ DAEC & 3 & $(1,9)$ & 0 & \\
\hline EAEC+ Rotavírus & 3 & $(1,9)$ & 0 & \\
\hline EAEC+ Shigella $s p$ & 1 & $(0,7)$ & 0 & \\
\hline EAEC+ $\mathbf{S}+\mathbf{R}$ & 1 & $(0,7)$ & 0 & \\
\hline DAEC+ Rotavírus & 8 & $(5,1)$ & 0 & \\
\hline DAEC+ Shigella sp & 2 & $(1,3)$ & 0 & $(2,4)$ \\
\hline DAEC+Giardia lamblia & 0 & & 1 & $(2,4)$ \\
\hline DAEC+ EAEC+ R & 1 & $(0,7)$ & 0 & \\
\hline Rotavírus + GL & 1 & $(0,7)$ & 0 & \\
\hline Casos negativos & 42 & $(27,2)$ & 33 & $(78,6)$ \\
\hline Total & 154 & $(\mathbf{1 0 0})$ & 42 & (100) \\
\hline $\begin{array}{l}\mathrm{E}=\text { Escherichia coli } \\
\mathrm{S}=\text { Salmonella } s p \\
\mathrm{R}=\text { Rotavírus } \\
\mathrm{GL}=\text { Giardia lamblia }\end{array}$ & & $\begin{array}{l}\text { EC-E Ent } \\
\text { EC-E Ente } \\
\text { EC-E Ente } \\
\text { EC-E Difu }\end{array}$ & $\begin{array}{l}\text { gênic } \\
\text { tênica } \\
\text { gativa } \\
\text { te agr }\end{array}$ & \\
\hline
\end{tabular}

habitual, a pesquisa de fatores de virulência com sondas genéticas ${ }^{28}$. Essas técnicas e métodos aumentaram a sensibilidade de detecção desses enteropatógenos (justificando também a elevada taxa de infecções mistas). Desta forma, na comparação dos presentes resultados com os de outros estudos, este diferencial metodológico deve ser considerado. Assim, os resultados de outras avaliações etiológicas anteriores, de nossa própria autoria como de outros, com percentuais de detecção de enteropatógenos situados entre 34 e $61,7 \%$ podem ser melhor compreendidas $4,12,19,20,22$.

A fração de casos do GDA com identificação de enteropatógenos foi muito maior do que no grupo sem diarréia. 
Tabela 4 - Perfil clínico, etário e socioeconômico das crianças do grupo com diarréia aguda (GDA), segundo a detecção de rotavírus e/ou bactérias enteropatogênicas

\begin{tabular}{|c|c|c|c|c|c|c|}
\hline $\begin{array}{l}\text { Agente } \\
\text { Parâmetro }\end{array}$ & $\begin{array}{c}\text { Bactéria } \\
\quad \text { (B) } \\
\mathbf{n}^{*}(\%)^{\dagger}\end{array}$ & $\begin{array}{c}\text { Rotavírus } \\
(\mathbf{R}) \\
\mathbf{n}^{*}(\%)^{\dagger}\end{array}$ & $\begin{array}{l}(\mathbf{B})+(\mathbf{R}) \\
\mathbf{n}^{*}(\%)^{\dagger}\end{array}$ & $\begin{array}{c}\text { Sem } \\
\text { (B) ou (R) } \\
\mathbf{n}^{*}(\%)^{\dagger}\end{array}$ & $\begin{array}{c}\text { Total } \\
\mathbf{n}^{*}(\%)^{\dagger}\end{array}$ & $\mathbf{p}$ \\
\hline № de casos & 54 & 33 & 25 & 42 & 154 & \\
\hline Idade $^{+}$média & 16 & 9,2 & 11,1 & 11,0 & 12,4 & 0,20 \\
\hline$<1$ ano & $33(33,0)$ & $23(23,0)$ & $17(17,0)$ & $27(27,0)$ & $100(100)$ & 0,11 \\
\hline Peso $<$ p10 & $7(30,4)$ & $3(13,1)$ & $7(30,4)$ & $6(26,0)$ & $23(100,0)$ & 0,20 \\
\hline RFM & 3,6 & 4,0 & 3,4 & 4,4 & 3,9 & 0,37 \\
\hline Leite materno" & $10(32,3)$ & $9(29,0)$ & $3(9,7)$ & $9(29,0)$ & $31(100,0)$ & 0,53 \\
\hline Evacuações/dia & 5,9 & 6,2 & 6,4 & 4,9 & 5,8 & 0,08 \\
\hline Febre & $28(30,7)$ & $23(25,3)$ & $15(16,5)$ & $25(27,5)$ & $91(100,0)$ & 0,40 \\
\hline Vômito"I & $8(18,2)$ & $11(25,0)$ & $16(36,4)$ & $9(20,4)$ & $44(100,0)$ & $\mathbf{0 , 0 1}$ \\
\hline Sangue/fezes & $9(52,9)$ & $2(11,8)$ & $1(5,9)$ & $5(29,4)$ & $17(100,0)$ & 0,27 \\
\hline Desidratação ${ }^{\S}$ & $7(18,9)$ & $10(27,1)$ & $11(29,7)$ & $9(24,3)$ & $37(100,0)$ & $\mathbf{0 , 0 1}$ \\
\hline Internação & $10(34,5)$ & $7(21,4)$ & $9(16,2)$ & $3(27,3)$ & $29(100,0)$ & $\mathbf{0 , 0 3}$ \\
\hline
\end{tabular}

* um caso com Giardia lamblia; B: bactéria; R: rotavírus; P: probabilidade; † \% da linha; § grave; "I exclusivo ou misto; I três ou mais episódios/24h; ¥ em meses; RFM: renda familiar média em salários mínimos/mês; p10: casos com peso inferior ao percentil 10 da curva do NCHS

Esses resultados reiteram que os patógenos avaliados estejam implicados na doença diarréica, como largamente reconhecido ${ }^{22,24}$. Porém, embora os dois grupos sejam constituídos majoritariamente por lactentes, deve ser ressalvado que diferem quanto à idade média.

\section{Perfil dos agentes encontrados}

Uma avaliação menos cuidadosa indicaria que as bactérias foram os agentes etiológicos mais importantes - detectadas em $51,3 \%$ das crianças do GDA versus $37,6 \%$ que apresentavam rotavírus (com elevado percentual de casos mistos). Porém, parte das bactérias poderia estar simplesmente atuando como um comensal, visto que estes microrganismos também foram detectados em $21,4 \%$ dos casos sem diarréia, o que não ocorreu com o rotavírus. Os protozoários tiveram escasso papel como enteropatógenos, em concordância com a maior parte dos estudos de diarréia, apesar de alguns ocasionais dados discrepantes ${ }^{5,20}$. Portanto, a importância relativa de rotavírus e de bactérias mostrou ser assemelhada no GDA, resultado que tem sido crescentemente observado em nosso país, assim como em outros em desenvolvimento ${ }^{12,24,25}$. Anteriormente, os estudos epidemiológicos indicavam um claro predomínio das bactérias, especialmente de Escherichia coli, da biovariedade EPEC ${ }^{4}$. Possivelmente, uma progressiva melhora das condições de higiene e de saneamento básico da população parece estar transformando o perfil etiológico da diarréia aguda $^{2,3,24}$.

Em relação ao perfil das bactérias potencialmente enteropatogênicas estudadas, Escherichia coli foi a espécie preponderante, como reconhecido pela literatura ${ }^{6,21}$. Foi identificada em $71(46,1 \%)$ casos de diarréia, e constituiu 90 das 105 cepas bacterianas isoladas nas crianças do GDA. O microrganismo mantém sua importância como enteropatógeno, ainda que se considere que parte destas Escherichia coli possa estar apenas colonizando o tubo digestivo de algumas das crianças do $\mathrm{GDA}^{21}$. Isto se depreende do achado da presença de Escherichia coli também em 9 $(21,5 \%)$ das crianças sem diarréia.

Das seis biovaridades de Escherichia coli, a EPEC, enteropatogênica clássica, foi um pouco mais freqüente (27 cepas) que as outras, como reconhecido previamente ${ }^{6,17}$. Foi detectada a presença de fatores de virulência EAF, BFP e EAE em $60 \%$ destas cepas (EPEC típicas), sendo as EPEC restantes classificadas como atípicas, aspecto já reconheci$\mathrm{do}^{20}$. Em conjunto, as biovariedades não EPEC preponderaram no GDA (63 versus 27 cepas), o que tem sido observado em outros locais ${ }^{11}$. Deve ser observada a ausência de EHEC no estudo, mesmo entre as crianças que apresentavam fezes sanguinolentas. Em outras avaliações, a EHEC esteve associada a 10-15\% das diarréias sanguinolentas ${ }^{17}$. EIEC também não foi detectada. A pequena incidência de EHEC e EIEC corroboram outras avaliações brasileiras 19,20 .

Um dado interessante é a reduzida porcentagem da EPEC identificada como agente único de diarréia no GDA$8,4 \%$, em relação a outros relatos que associam essa bactéria a 20 e até $30 \%$ dos $\operatorname{casos}^{12,18}$. Também a ETEC foi detectada como agente único da diarréia em 2,6\% dos casos do GDA, taxa semelhante à de alguns ${ }^{20}$, porém inferior às encontradas em outros estudos de países em desenvolvimento, que situam-se entre 10 e $33,5 \%$ 4,9,11. Em nosso 
estudo, foi observado um elevado percentual de casos com etiologia mista envolvendo a EPEC $(9,1 \%)$ e a ETEC $(11,1 \%)$. Parece-nos que as taxas reduzidas de detecção isolada de EPEC e ETEC decorram do elevado percentual de concomitância de outros enteropatógenos. Possivelmente, a otimização das técnicas de detecção viral e bacteriana utilizadas no presente estudo seja responsável por estes dados.

Outras biovariedades de Escherichia coli diarreiogênicas detectadas no GDA, EAEC (19 cepas) e DAEC (23 cepas) não são habitualmente avaliadas nos laboratórios clínicos, e mesmo em alguns estudos etiológicos ${ }^{12,14,20}$. Portanto, pode-se inferir que parte dos quadros diarréicos não obteria elucidação etiológica caso fosse avaliada fora do protocolo de pesquisa.

As associações de diferentes biovariedades de Escherichia coli ocorreram em 17 casos do GDA, sendo que em 3 destes foi detectado concomitantemente rotavírus. Portanto, foram $14(9,1 \%)$ as associações apenas de biovariedades de Escherichia coli encontradas no GDA, e uma $(2,4 \%)$ no GSDA, proporções não diversas ( $\mathrm{p}=0,33$ ). Isso não evidencia um possível efeito sinérgico destas biovariedades em relação à ocorrência de quadros diarréicos.

Das outras bactérias identificadas no GDA, destaca-se a Shigella $s p$, que foi isolada em 12 casos $(7,8 \%)$, em metade destes, como único patógeno. Na maioria eram Shigella flexneri. Outros estudos em populações carentes observaram freqüência e espécie semelhante deste enteropatógeno em crianças diarréicas $7,12,18,19,22$. Por vezes, o percentual de encontro da Shigella $s p$ foi maior ${ }^{20}$. A pequena taxa de detecção da Salmonella sp, observada no GDA, acompanha a progressiva redução verificada nos países latino-americanos, a partir dos anos $90^{19,20}$. Campylobacter sp e Yersinia sp também mostraram escassa importância no grupo diarréico, assim como verificado em outros estudos brasileiros ${ }^{4,13,20}$.

Foi elevada a fração de casos do GDA em que foi detectado rotavírus (37,6\%- 58 crianças), sendo que em 31 $(20,1 \%)$ era o único patógeno. Esses resultados ficaram valorizados pela não detecção do vírus em qualquer criança do GSDA. Outros autores também têm identificado rotavírus em, no máximo, 3 a $5 \%$ de crianças sem diarréia ${ }^{24}$. Poderíamos, até, ter verificado um papel ainda maior para o agente, caso se tivesse também pesquisado rotavírus de grupos não-A. Estes últimos têm sido detectados em pequena parcela das crianças com diarréia, como mostraram alguns autores ${ }^{25}$.

O rotavírus estava associado a bactérias em 25 (16,3\%) dos casos do GDA. Essa simultaneidade foi observada previamente, porém em menor proporção $0^{4,20}$. O elevado percentual da associação rotavírus/bactéria verificado no presente estudo, em relação a outros, pode decorrer simplesmente de uma otimização da metodologia ${ }^{20}$.

A elevada frequiência de rotavírus do presente estudo está em consonância com os estudos mais recentes da literatura, que apontam uma crescente proporção do agente como causador de diarréias, mesmo nos países em desenvolvimento ${ }^{24}$. Essa tendência é verificada a partir da década de 80, tanto para casos graves (internados) como leves (ambulatoriais) $)^{5,9,14}$. O aumento da proporção de rotavírus entre os casos de diarréia não parece resultar de um aumento de incidência ${ }^{2,3}$. Os indicadores de saúde têm mostrado redução da incidência de gastrenterites em geral, principalmente dos quadros bacterianos, resultando no aumento relativo dos quadros virais ${ }^{2,3}$.

Em relação aos aspectos clínicos e achados etiológicos do estudo, foram reiteradas algumas conclusões já observadas por outros autores. De modo geral, as características clínicas dos casos têm limitada especificidade e, portanto, reduzida utilidade clínica ${ }^{1-3}$. A intensidade da diarréia, a presença de sangue nas fezes, a idade do paciente, a febre e a estação climática não possibilitam determinar o agente ou família de agentes causadores de diarréia ${ }^{12}$. Foram constatadas maiores freqüências de biovariedades de $E s$ cherichia coli em lactentes pequenos durante os meses mais quentes e de rotavírus nos meses de outono e inverno, a exemplo do que se observou em outros estudos ${ }^{4,20,24}$. Foi, também, verificada correlação entre os casos mistos bacterianos e virais, com um perfil clínico de doença mais grave - com maior percentual de vômitos, desidratação e internação. Mas as análises bivariadas realizadas constituem reduzida evidência destas correlações. De modo geral, todos estes achados têm restrita utilidade para o clínico.

\section{Conclusão}

Os autores estudaram a etiologia da diarréia em um grupo grande de crianças, socioeconomicamente carentes, atendidas durante um período extenso em pronto-atendimento. Verificaram que a Escherichia coli e o rotavírus são encontrados na maior parte dos casos, inclusive associados, nos mesmos doentes. Os protozoários tiveram escassa importância. Um percentual dos casos do GDA permaneceu sem identificação causal, indicando, indiretamente, que outros potenciais patógenos já reconhecidos possam estar implicados ${ }^{13-15}$. A maior parte das Escherichia coli detectadas pertencem a biovariedades freqüentemente não avaliadas rotineiramente nos laboratórios clínicos. Essa observação, aliada às de outros estudos, possibilita sugerir ao pediatra clínico que quadros diarréicos sem esclarecimento etiológico possam resultar de limitações técnicas na investigação bacteriana ${ }^{20}$.

Sob outro ângulo, apesar do progresso na detecção de enteropatógenos, a limitação do conhecimento relativo à fisiopatogia da diarréia ficou, também, evidente. No presente estudo, foi detectado no GSDA um percentual significativo de crianças com bactérias reconhecidas como patogênicas, mas que não apresentavam diarréia. Também foram detectadas cepas de EPEC, sem que os fatores de virulência pudessem ser reconhecidos. Esses aspectos, já previamente observados, reiteram que a patogenia depende de fatores do agente e/ou do hospedeiro, que ainda hoje não estão bem identificados ${ }^{17}$. 
O reconhecimento de causa infecciosa na maioria das diarréias investigadas no presente estudo, como em ou$\operatorname{tros}^{2}$, indicam a necessidade de estimular medidas profiláticas $^{2}$. Para o grupo de crianças atendido no pronto-atendimento, assim como para outros assemelhados, a profilaxia dos quadros bacterianos deve ser enfocada com base nos programas de saúde primária (amamentação, higiene pessoal e melhora das condições sanitárias), como já estabelecido $^{1}$. Quanto à profilaxia das infecções por rotavírus, de importância crescente, deve ser reforçado o empenho no desenvolvimento de vacina eficaz e segura ${ }^{24}$.

\section{Agradecimentos}

A pesquisa de fatores de virulência das Escherichia coli foram realizadas pela Dra. Tânia Tardelli Gomes, da Universidade Federal de São Paulo. Os soros hiperimunes utilizados neste estudo foram fornecidos pela PROBAC ${ }^{\circledR}$ do Brasil. Ao Dr. Celso Rebello, pelas sugestões apresentadas.

\section{Referências bibliográficas}

1. Victora CG, Fuchs SC. Breast-feeding, nutritional status, and other prognostic factors for dehydration among young children with diarrhoea in Brazil. Bull Wld Hlth Organ1992;70:467-75.

2. Bern C, Martines J, de Zoysa I, Glass RI. The magnitude of the global problem of diarrhoeal disease: A ten-year update. Bull WHO1992;70:705-14.

3. Datasus - Ministério da Saúde, Secretaria Executiva. Indicadores Básicos de Saúde - Brasil-1997 (IBD-97): http: //www.datasus. gov.br/, 07/12/1999.

4. Gomes TA, Rassi V, Mac Donald KL, Ramos SR, Trabulsi LR, Vieira MA, et al. Enteropathogens associated with acute diarrheal disease in urban infants in São Paulo, Brazil. J Infect Dis 1983;148:986-97.

5. Baltazar JC, Tiglao TV, Tempongko SB. Hygiene behaviour and hospitalized severe childhood diarrhoea: a case-control study. Bull WHO 1993;71:323-8.

6. Blacke PA, Ramos S, MacDonald KL, Rassi V, Gomes TAT, Ivey C, et al. Pathogen-specific risk factors and protective factors for acute diarrheal disease in urban Brazilian Infants. J Infect Dis 1993; 167:627-32

7. Guerrant RL, Hughes JM, Lima NL, Crane J. Diarrhea in developed and developing countries: magnitude, special setting, and etiologies. Rev Infect Dis 1990;12(S):41S-50S.

8. Gomes TAT, Blake PA, Trabulsi LR. Prevalence of Escherichia coli strains with localized, diffuse, and aggregative adherence to HeLa cells in infants with diarrhea and matched controls. J Clin Microbiol 1989;27:266-9.

9. Mangia AHR, Duarte NA, Duarte R, Silva LA, Bravo VLR, Leal MC. Aetiolology of acute diarrhoea in hospitalized children in Rio de Janeiro City, Brazil. J Trop Pediatr 1993;39:365-7.

10. Stewien KE, Mós EN, Yanaguita RM, Jerez JA, Durigon EL, Hársi $\mathrm{CM}$, et al. Viral, bacterial and parasitic pathogens associated with severe diarrhoea in the City of São Paulo, Brazil. J Diarrh Dis Res 1993;11:148-52.

11. Abu-ElYazeed R, Wierzba TF, Peruski LF, Kay BA, Rao M, Churilla AM, et al. Epidemiology of enterotoxigenic Escherichia coli diarrhea in a pediatric cohort in a periurban area of lower Egypt. J Infect Dis1999;179:382-9.

12. Toporovski MS, Mimica I, Chieffi PP, Paschoalotti MA, Dias AM, Silva CB. Diarréia aguda em crianças menores de 3 anos de idade: recuperação de enteropatógenos nas amostras fecais de pacientes comparada à de grupo controle. J Pediatr (Rio J) 1999;75:97-104.
13. Johnson RH. Yersinia infections. Curr Sci 1992;5:654-8.

14. Timenetsky MCST, Kisielius JJ, Grisi SJFE, Escobar AMU, Ueda M, Tanaka I. Rotavírus, adenovírus, astrovírus, calicivírus e "small round virus particles" em fezes de crianças com e sem diarréia aguda, no período de 1987 a 1988, na Grande São Paulo. Rev Inst Med Trop São Paulo 1993;35:275-80.

15. Harsi CM, Rolim DP, Gomes AS, Gilio AE, Stewien KE, Baldacci ER, et al. Adenovirus genome types isolated from stools of children with gastroenteritis in São Paulo, Brazil. J Med Virol 1995;45:127-34.

16. Levine MM, Edelman R. Enteropathogenic Escherichia coli of serotypes associated with infant diarrhea. Epidemiology and Pathogenesis. Epidemiol Rev 1984;8:31-61.

17. Nataro JP, Kaper JB. Diarrheagenic Escherichia coli. Clin Microbiol Ver 1998;11:142-201.

18. Scaletsky ICA, Pedroso MZ, Oliva CAG, Carvalho RLB, Morais $\mathrm{MB}$, Fagundes-Neto U. A localized adherence-like pattern as a second pattern of adherence of classic enteropathogenic Escherichia coli to Hep-2 cells that is associated with infantile diarrhea. Infect Immun 1999;67:3410-5.

19. Kitagawa SMS, Toledo MRF, Trabulsi LR, Ramos SRTS, Murahovisch J, Fagundes-Neto U, et al. Etiologia da diarréia infecciosa endêmica da criança de baixo nível sócio-econômico em São Paulo. Am J Trop Med Hyg 1986;35:1013-22.

20. Almeida MTG, Silva RM, Donaire LM, Moreira LE, Martinez MB. Enteropatógenos associados com diarréia aguda em crianças. J Pediatr (Rio J) 1998;74:291-8.

21. Osmo AA, Araújo MC, Barison E, Gilio AE, Bernabe AL, Carneiro $\mathrm{RG}$, et al. Estudo etiológico de 252 casos de diarréia aguda internados nos Hospital Universitário da Universidade de São Paulo. Pediatr (S Paulo) 1983;5:175-83.

22. Gilio AE, Terra CM, Fenerich TC, Baldacci ER, Okay Y, Issa RMN, et al. Etiologia da diarréia aguda em crianças do sub-distrito do Butantã atendidas ambulatorialmente em hospital geral. Pediatr (S Paulo) 1991;13:68-70.

23. Linhares AC, Gabbay YB, Mascarenhas JDP, Freitas RB, Flewett $\mathrm{TH}$, Beards GM. Epidemiology of rotavirus subgroups and serotypes in Belém, Brazil: a three-year study. Ann Virol (Inst Pasteur) 1988;139:89-99.

24. Cunliffe NA, Kilgore PE, Breese JS, Steele AD, Luo N, Hart CA, et al. Epidemiology of rotavirus diarrhoea in Africa: a review to assess the need for rotavirus immunization. Bull Wld Hlth Organ 1998;76:525-37.

25. Gusmão RH, Mascarenhas JD, Gabbay YB, Lins-Lainson Z, Ramos FL, Monteiro TA, et al. Rotavirus subgroups, G serotypes, and electrophoretypes in cases of nosocomial infantile diarrhoea in Belém, Brazil. J Trop Pediatr 1999;45:81-6.

26. Sereny B. Biochemical reactions and virulence of E. coli O 124:K72 (B17). Acta Microbiol Acad Sci Hung 1963;10:11-8.

27. Edwards PR, Ewing WH. Identification of Enterobacteriaceae. $3^{\text {a }}$ ed. Minneapolis: Burgess; 1972. p.536-603.

28. Mass R. An improved colony hybridization method with significant sensitivity for detection of single genes. Plasmid 1983;10:296-8.

29. Pereira HG, Azeredo RS, Leite JPG, Andrade ZP, Castro L. A combined enzyme immunoassay for rotavirus and adenovírus. $\mathrm{J}$ Virol Meth 1985;10:21-8.

30. Faust EC, D'Antoni JS, Odan W, Miller MJ, Peres C, Sawitz W, et al. Critical study of clinical laboratory techniques for diagnosis of protozoan cysts and helminth eggs in feces: preliminary communication. Am J Trop Med 1938;18:169-83.

Endereço para correspondência:

Dra. Eloisa Correa Souza

Hospital Universitário da USP- Divisão de Pediatria

Av. Linneu Prestes, 2565 - Cidade Universitária

CEP 05508-900 - São Paulo, SP

Fone: 113818.7757 - Fax: 1138128004

E-mail: dcp_1@hu.usp.br 